\title{
Analysis on Force Transmission Characteristics of Two-Legged Shield Support under Impact Loading
}

\author{
Qing-liang Zeng $\mathbb{D}^{D}$, Zhao-sheng Meng ${ }^{(D)}$, Li-rong Wan, and Cheng-long Wang \\ College of Mechanical and Electronic Engineering, Shandong University of Science and Technology, Qingdao 266590, China \\ Correspondence should be addressed to Qing-liang Zeng; qlzeng@163.com and Zhao-sheng Meng; skdmzs@163.com
}

Received 11 September 2017; Accepted 21 January 2018; Published 15 March 2018

Academic Editor: Edoardo Sabbioni

Copyright (C) 2018 Qing-liang Zeng et al. This is an open access article distributed under the Creative Commons Attribution License, which permits unrestricted use, distribution, and reproduction in any medium, provided the original work is properly cited.

\begin{abstract}
To study the load transfer characteristics of a two-legged shield powered support, a numerical simulation model of the support was established using the multibody dynamics software ADAMS. The model took full account of the hydraulic-elastic deformation characteristics of the support, as a series spring-damper system was used to replace the leg and the equilibrium jack. The canopy, goaf shield, lemniscate bars, and equilibrium jack are equivalent to flexible bodies. The setting force of the leg was provided by the preload of the equivalent spring, the static roof load was simulated using a slope signal, and the impact load was simulated using a step signal. Using the model, the impact and excitation effects of each hinge joint of the support were analyzed under different impact load conditions across the canopy. The results show that the location of the impact load affects the force transmissions of all hinge points of the support. Both the impact effect and the excitation effect are at a minimum when the impact force is located near the leg action line. These results are useful for the adaptive control and structural design optimization of the support.
\end{abstract}

\section{Introduction}

Self-advancing hydraulic support is a technically proven and well-established technique for longwall mining. It helps to hold the face, push the armored face conveyor (AFC), and provide a safe environment for all underground mining operations [1]. Its adaptability to roof loading is a key factor in the safe and efficient production of the working face $[2,3]$. The type of loads applied to the shield supports in longwalls can be divided into two categories, namely, static load of the working face (the gravity load of the overlying strata) and impact load [4-6]. Among them, the impact load is the main cause of the support damage. Therefore, studying the dynamic response and force transmission of the shield support under impact loading is helpful for the strength design of the support and safe operations at the working face. Since the effect of impact loading on coal mining operations is very huge, scholars all over the world have studied the influencing factors of the impact load on the shield support and the decisions behind reasonable shield support capacity. For instance, the authors of [7-9] studied the influence of geological conditions on the rock burst tendency using a
Finite Element Method. The research reported in [10-15] constructed the numerical model of stope and studied the influence of the rock burst on the support load. Pioneering work presented in [16-19] showed that data from monitoring systems (instrumentation) or shield control systems could be used to predict the occurrence time of the impact load. The supports are treated as mechanic-elastic structures in the above literatures and hydraulic-elastic deformation characteristics of the legs are neglected. Literature [20] studied the dynamic response of the support system when an impact load is applied, and the leg is regarded as a linear elastic structure. Up until now, few literatures have taken the varying characteristics of the leg stiffness into consideration.

Given the disparity identified in previous studies, this paper investigates the varying characteristics of the leg stiffness and an equivalent stiffness model of a doubly telescopic leg under isentropic condition was established. Subsequently, a large cutting height shield support was taken as an example. A multibody dynamic model of the support was constructed using ADAMS. By using an equivalent stiffness model, the doubly telescopic leg is equivalent to an elastic element with variable stiffness. The force transfer coefficient variation law 


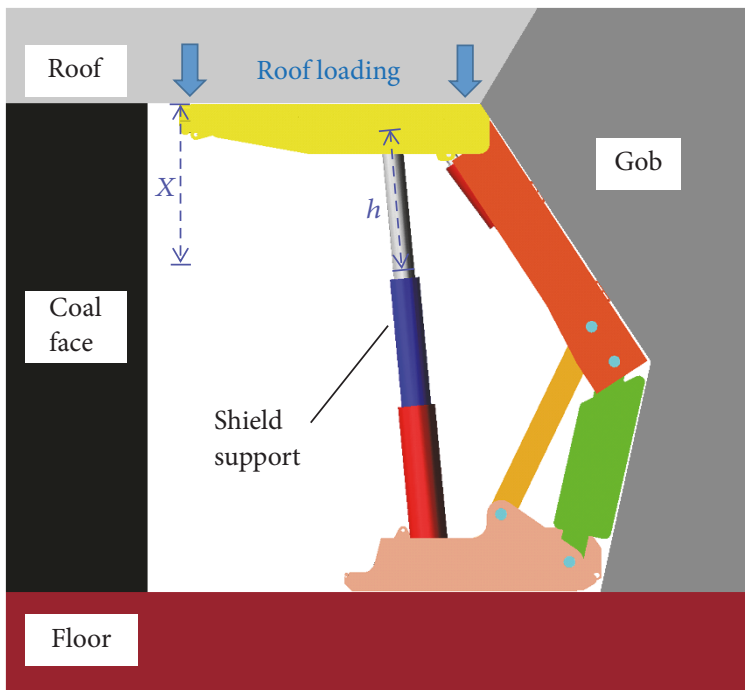

FIGURE 1: Supporting schematic diagram of a shield support.

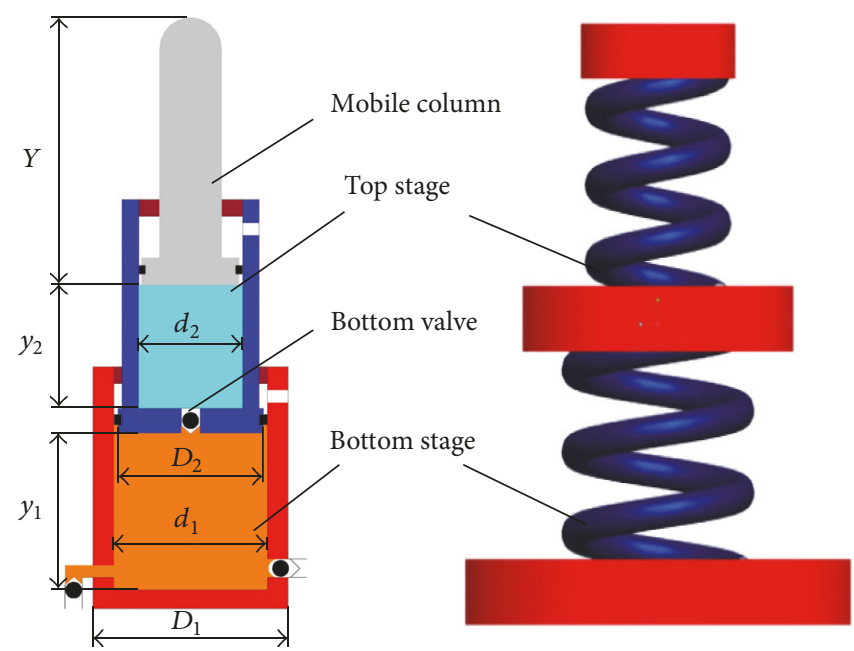

FIgURE 2: The doubly telescopic leg and its equivalent spring model.

at the hinge point of the support was studied considering that the impact load was applied at different locations along its canopy.

This paper is arranged as follows. In Section 2, the derivation of the equivalent stiffness model is presented. This includes a holistic analysis of the working process of a shield support along with the mathematical formulation of a doubly telescopic leg. In Section 3, a numerical multibody dynamics model of the selected shield support is established. A series spring-damper system (based on the stiffness model described in Section 2) is used to replace the leg and the equilibrium jack. The model is then tested to verify whether the simulations satisfy the precision requirements for the subsequent analysis. In Section 4, the influence of the impact loading position on the hinge point force is analyzed. Finally, conclusions are drawn in Section 5.

\section{Equivalent Stiffness Analysis Model of a Doubly Telescopic Leg}

2.1. Analysis of the Working Process of a Shield Support. A typical working cycle of a shield support is the period from the time it is set against the roof to the time when it is released for advancing after the shearer has made its pass [18]. During this process, the role of the supports is to control the roof from an excessive roof-to-floor convergence $X$, as shown in Figure 1. $X$ is determined by the displacement of the leg $h$.

Previous studies have analyzed the working process of the support according to its rate of pressure change, segmented into three sections $[16,18]$. In this paper, the working process of the support, with doubly telescopic legs (Figure 2), is redefined as five segments from the point of view of its stiffness variations. As can be seen from Figure 2, the leg 


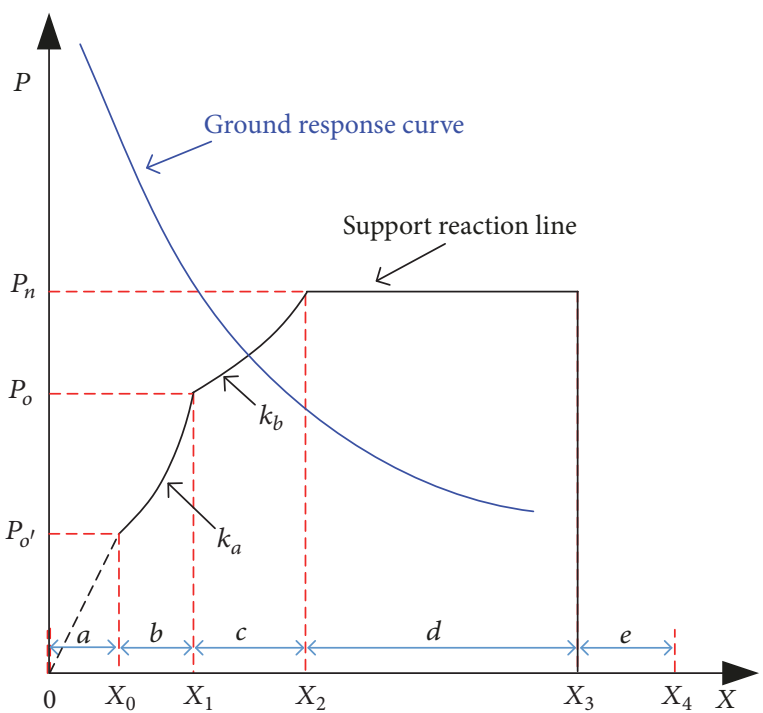

FIGURE 3: Working curve of the shield support.

is equivalent to a series spring model (the calculation of its stiffness is given in Section 2.2). $Y$ is the length of the mobile column, $y_{1}\left(y_{2}\right)$ is the length of the emulsion in the bottom stage (top stage), and $D_{1}\left(D_{2}\right)$ and $d_{1}\left(d_{2}\right)$ are the external and internal diameters of the bottom stage (top stage), respectively.

Figure 3 shows the working curve of a shield support during a whole working cycle. $X_{0} \sim X_{4}$ are the displacements of the roof and the support at different stages, respectively. $P_{\mathrm{O}^{\prime}}$ is the active setting pressure of the support, $P_{\mathrm{O}}$ is the effective pump pressure (passive setting pressure), and $P_{n}$ is the yielding pressure of the relief valve. $k_{a}\left(k_{b}\right)$ is the stiffness of the support at stage b (stage $c$ ). Figure 4 represents the working process of the doubly telescopic leg (before reaching $\left.P_{n}\right)$ by using the equivalent spring model. $h_{1}\left(h_{2}\right)$ is the displacement of the top stage (bottom stage).

According to Figures 3 and 4, the five segments of the working process of the support are as follows. The first segment is the active setting (stage a). The shield support is set against the roof using $P_{O}$. Due to the pressure loss of the bottom valve and smaller diameter of the top stage, the active setting force $P_{O^{\prime}}$ formed by the leg is usually less than $P_{O}$. In this portion, the roof loading $P$ is transferred to the support gradually (Figure $4(\mathrm{a})$ ). However, the load is smaller than $P_{\mathrm{O}^{\prime}}$ and the leg does not retract $\left(X_{0}=0\right)$. When $P$ is bigger than $P o^{\prime}$ (Figure 4(b)), the top stage begins to retract with the stiffness of $k_{a}$ (stage $\mathrm{b}$ ). As the roof pressure continues to rise, the support enters the third segment-the rapid increase (stage $\mathrm{c}$ ). At this time, both stages of the leg retract, resulting in the reduction of the equivalent stiffness (Figure $4(\mathrm{c})$ ). As the roof pressure continues to rise to $P_{n}$, the support enters into the overflow segment. At this point, the retracting speed of the support is determined by the performance of the relief valve. Displacement formed in this stage is irreversible; therefore, it can be referred to as the "plastic deformation segment." The final segment (stage e) is the release segment. The roof loading applied to the hydraulic support decreased rapidly and the leg retracted quickly.
The ground response curve (GRC) theory [19, 21-24] suggests that the factor that determines the suitability of the shield support is the stiffness of the support. It holds the view that if the GRC and support reaction line intersect before stage $d$, the selected support is considered to be reasonable and effective. This type of stiffness analysis of the support was reported previously [25], but the plastic deformation characteristic of the support was neglected in the study.

2.2. Mathematical Model of an Equivalent Stiffness Doubly Telescopic Leg. Assuming that the compression deformation process is an isobaric expansion under the isentropic condition, the stiffness of a single-telescopic cylinder can be determined using the following equation:

$$
K_{z}=\frac{1}{1 / K_{l}+1 / K_{p}}=\frac{1}{\left(h_{l}+h_{e}\right) / F_{p}+Y / E_{h} A_{h}},
$$

where $K_{z}$ is the equivalent stiffness of the single-telescopic leg, $K_{l}$ is the equivalent stiffness formed by cylinder expansion and emulsion compression, $K_{p}$ is the stiffness of the piston, $h_{l}$ is the compression length of the emulsion, $h_{e}$ is the displacement of the rod caused by cylinder wall expansion, $F_{p}$ is the axial force applied on the piston rod, $E_{h}$ is the elastic modulus of the rod, and $A_{h}$ is the cross-sectional area of the rod.

$h_{e}$ can be calculated using the deformation theory of thick-walled cylinders (the leg is a typical high pressure thick wall structure). Combining the force equilibrium equations and geometric equations of the elements, the deformation equation of the cylinder can be expressed as

$$
\frac{d^{2} u}{d r^{2}}+\frac{1}{r} \frac{d u}{d r}-\frac{u}{r^{2}}=0
$$

where $u$ is the radial displacement of the cylinder and $r$ is diameter of the cylinder. Substituting the boundary condition (see (3)) into (2) and ignoring the atmospheric pressure, the analytical solution for the radial displacement of the leg can be expressed as (4).

$$
\begin{aligned}
\sigma_{r=d} & =p, \\
\sigma_{r=D} & =p_{2}, \\
u & =\frac{\Delta p d m}{2 E_{g}},
\end{aligned}
$$

where $m=\left((1+\mu) D^{2}+(1-\mu) d^{2}\right) /\left(D^{2}-d^{2}\right), \Delta p=p-p_{2} \approx p$, $\mu$ is Poisson's ratio, $d$ is the internal diameter of the cylinder, $D$ is the external diameter of the cylinder, $p$ is the cylinder pressure, $p_{2}$ is the atmospheric pressure, and $E_{g}$ is the elastic modulus of the cylinder. Then the expansion volume of the leg $\Delta V_{g}$ can be expressed as (5) and $h_{e}$ can be obtained using (6).

$$
\begin{aligned}
\Delta V_{g} & =\pi d^{2} \frac{y \Delta p m}{2 E_{g}}, \\
h_{e} & =\frac{\Delta V_{g}}{A}=2 y \Delta p \frac{m}{E_{g}},
\end{aligned}
$$


TABLE 1: The main parameters of the doubly telescopic leg.

\begin{tabular}{lccc}
\hline Name of the project & Top stage & Bottom stage & Mobile column \\
\hline Structure length $Y(\mathrm{~mm})$ & $/$ & $/$ & 2113 \\
Initial emulsion length $y_{i}(\mathrm{~mm})$ & $/$ & 1.9 & 2197 \\
Quality $(t)$ & 2.1 & $500 / 380$ & 1.276 \\
External/internal diameter $D_{i} / d_{i}(\mathrm{~mm})$ & $625 / 530$ & $34 / 92.6$ & 355 \\
Setting/yielding pressure $P_{o} / P_{n}(\mathrm{MPa})$ & $37.5 / 47.6$ & $196\left(20^{\circ} \mathrm{C}\right)$ \\
Modulus of elasticity $(\mathrm{GPa})$ & & 0.3 & $/$ \\
Poisson's ratio & & 0.3 \\
\hline
\end{tabular}

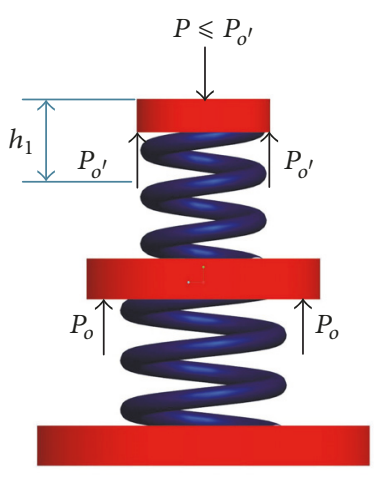

$X_{0}=f\left(h_{1}\right)=0$

(a) Stage a

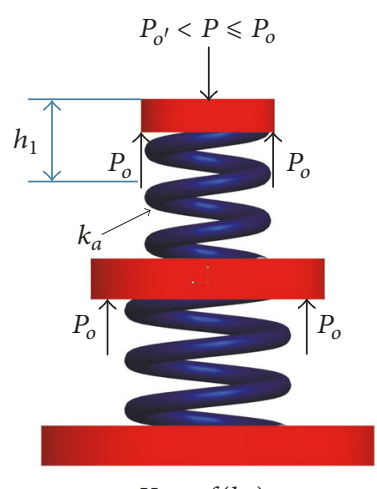

$X_{1}=f\left(h_{1}\right)$

(b) Stage b

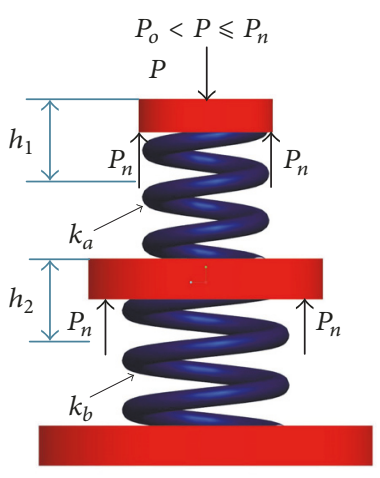

$X_{2}=f\left(h_{1}+h_{2}\right)$

(c) Stage c

FIGURE 4: Working process of the doubly telescopic leg.

where $A$ is the internal cross-sectional area of the cylinder. $h_{l}$ can be obtained using the compressible fluid theory (see (7)).

$$
h_{l}=\frac{4 \kappa V_{0} \Delta p}{\pi d^{2}}=\kappa \Delta p y
$$

where $\kappa$ is the compressibility of the emulsion and $V_{0}$ is the initial volume of the emulsion.

By combining (1), (6), and (7), the formula for calculating the equivalent stiffness of $i$ th stage cylinder is given by

$$
K_{z i}=\frac{\Delta F_{z i}}{h_{i}}=\frac{\pi E_{g} A_{h}}{\left(\left(4 \kappa y_{i} / d_{i}^{2}\right) E_{g}+8 y_{i}\left(m_{i} / d_{i}^{2}\right)\right) A_{h}+\pi Y},
$$

where $K_{z i}$ is the equivalent stiffness of $i$ th stage cylinder, $\Delta F_{z i}$ is the larger part of the load experienced by stage $i$, and $h_{i}$ is the displacement of the rod of stage $i$. If the volume force acting on the fluid is neglected, $\Delta F_{z i}=\Delta F_{p}$.

For a doubly telescopic cylinder, it can be regarded as a series spring system (Figure 2). Then its stiffness can be calculated as [18]

$$
K=\frac{K_{z 1} K_{z 2}}{K_{z 1}+K_{z 2}}
$$

where $K$ is the equivalent stiffness of doubly telescopic leg.

2.3. Case Study. A certain type of shield support was taken as an example in this section. The main parameters of the leg are shown in Table 1 (Figure 2) and its equivalent stiffness

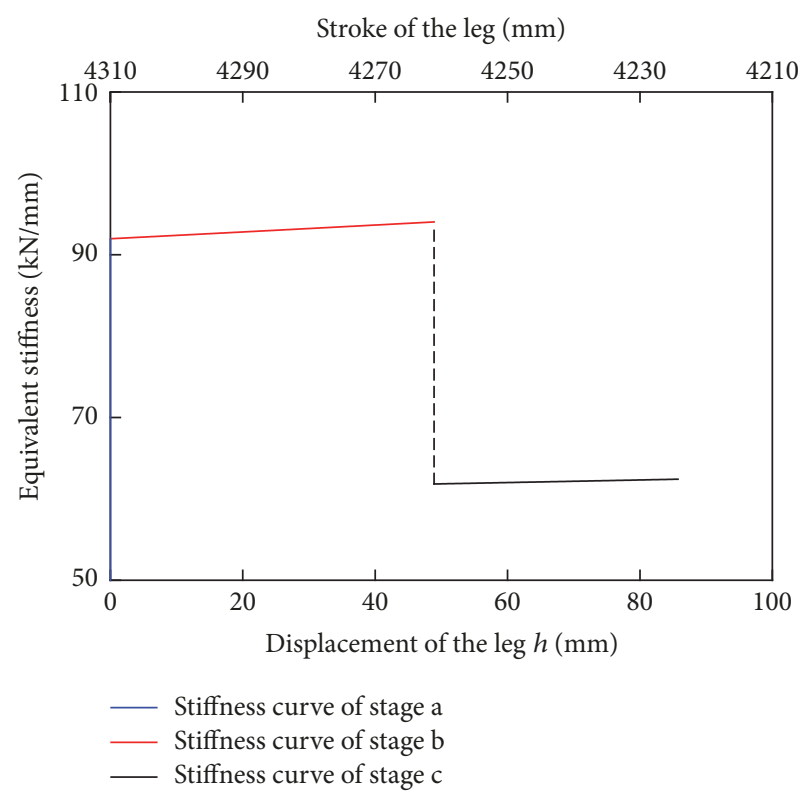

FIGURE 5: Stiffness variation curve of the doubly telescopic leg.

was calculated using (9). It is assumed that $P o^{\prime}$ is $34 \mathrm{MPa}$ (the active setting force is about $3856 \mathrm{kN}$ ). The results obtained by using (9) are shown in Figure 5. Lines OA, AB, and CD represent the stiffness of the leg at stage $a$, stage $b$, and stage c, respectively. 


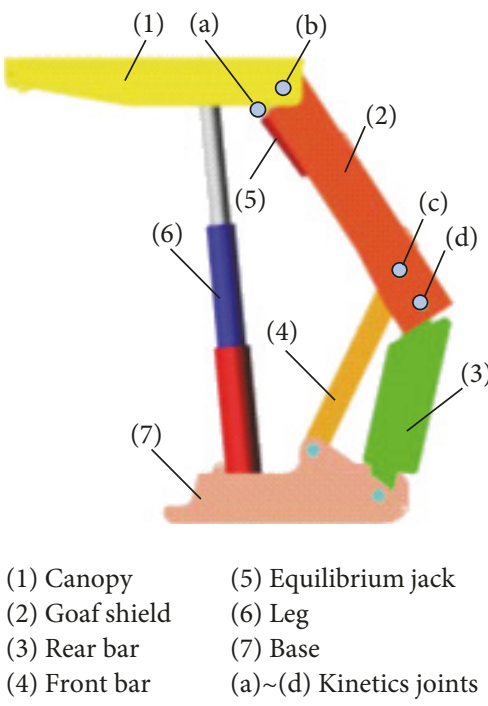

(a) Prototype model of the support

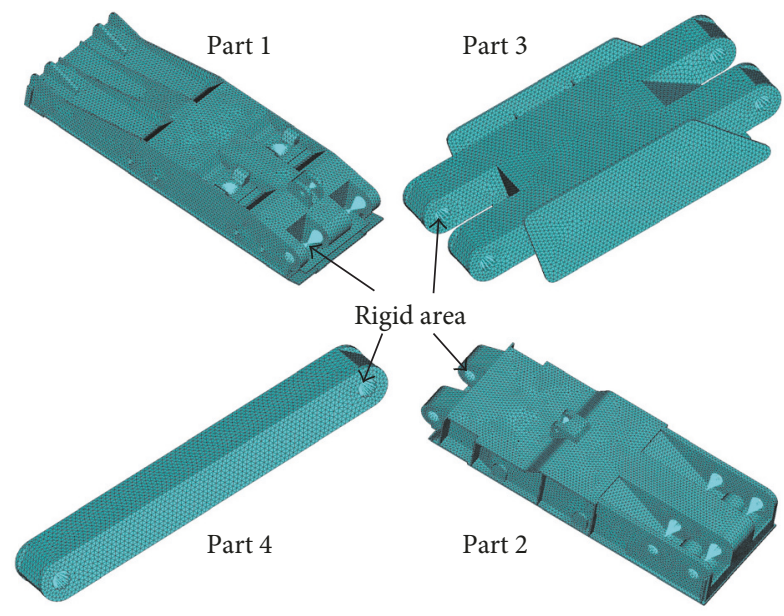

(b) Grid model of the key parts of the support

FIGURE 6: Model of the shield support.

The above settings are substituted into (10) and the calculated results are compared with the actual parameters of the support.

$$
\begin{aligned}
& \dot{F_{P_{\mathrm{O}}}}=F_{P_{\mathrm{O}^{\prime}}}+\int_{O}^{B} K_{z} d x=8394 \mathrm{kN}, \\
& \dot{F_{P_{n}}}=F_{P_{\mathrm{O}^{\prime}}}+\int_{O}^{D} K_{z} d x=10683 \mathrm{kN},
\end{aligned}
$$

where $F_{P_{\mathrm{O}}}$ is the calculated value of the setting force and $F_{P_{n}}$ is the calculated value of the yielding resistance. The error estimate is shown in (11). Given the fact that the errors are less than $5 \%$, the calculation results of formula (9) are deemed to be of high accuracy.

$$
\begin{aligned}
& \delta_{F_{P_{O}}}=\frac{\left(\dot{F_{P_{O}}}-F_{P_{\mathrm{O}}}\right)}{F_{P_{\mathrm{O}}}}=1.462 \%, \\
& \delta_{F_{P_{n}}}=\frac{\left(\dot{F_{P_{n}}}-F_{P_{n}}\right)}{F_{P_{n}}}=1.743 \%,
\end{aligned}
$$

where $F_{P_{O}}$ is the rated setting force $(8273 \mathrm{kN})$ and $F_{P_{n}}$ is the rated working resistance $(10500 \mathrm{kN})$.

\section{Numerical Multibody Dynamics Model of the Shield Support}

3.1. Preparation of the Simulation Model. The selected prototype of the support is shown in Figure 6(a). Its operating height ranges from $3.8 \mathrm{~m}$ to $8.2 \mathrm{~m}$ and its working resistance reaches up to $21000 \mathrm{kN}$. The canopy, goaf shield, front bar, and rear bar are modelled as flexibles using HyperMesh (Figure 6(b)). The data are transferred to ADAMS in MNF format. The base is fixed on the ground as a rigid body; the legs are replicated using the equivalent stiffness model

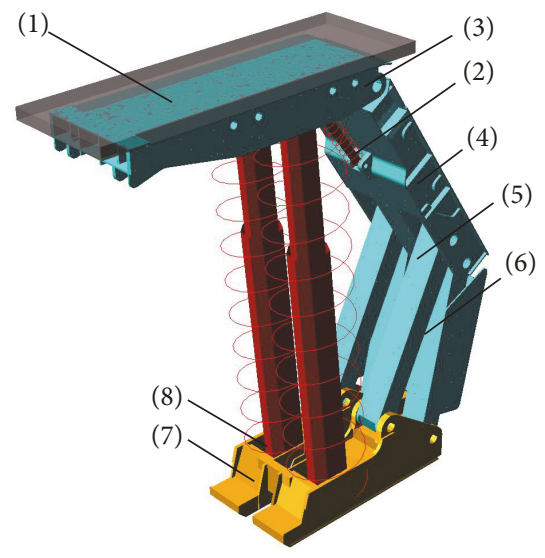
(1) Simulated roof
(2) Equivalent spring
(3) (6) Flexible parts
(7) Rigid part
(8) Equivalent spring

Figure 7: Numerical model with the simulated roof.

described in Section 2.3. Given the fact that the equilibrium jack is single extension with asymmetric tension and compression characteristics, it is modelled as a constant stiffness spring.

3.2. The Simulation Experiment of the Support under Normal Working Conditions. The aim of the simulation test is to preliminarily verify whether the simulation model could satisfy the precision requirements for the subsequent tests. In order to simulate the stress state of the support more realistically, a simulated roof is placed on the canopy. The simulated roof can rotate freely in the horizontal plane and it connects with the roof at impact (Figure 7). Applying a 


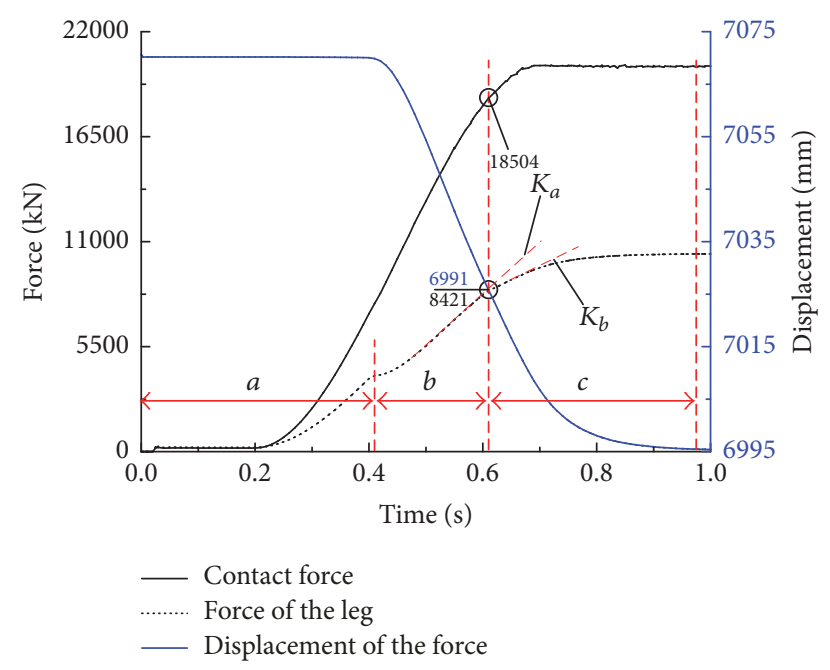

Figure 8: Dynamic response curves of the leg system.

vertical downward static load of $20000 \mathrm{kN}$ to the simulated roof, the response of the leg system is shown in Figure 8. As shown in the figure, the contact force increases to $18504 \mathrm{kN}$ in $0.7 \mathrm{~s}$ (part of the load is bore by the equilibrium jack) and then remains stable. The load on the single leg is approximately half of the contact force $(8421 \mathrm{kN})$. As mentioned previously, the elastic deformation process of the support can be divided into three segments (the lifting segment and the releasing segment are not included). Stage a is the active setting. In this portion, the roof load applied on the support is smaller than the active setting force $(3856 \mathrm{kN})$, so essentially the support does not lower (due to the extra gravity of the simulated roof, the support lowers about $0.6 \mathrm{~mm}$ ). In stage $b$, the roof load increases gradually beyond the setting force of the leg and the displacement of the roof decreased linearly. When the working resistance of the leg reaches $8421 \mathrm{kN}$, the rapid increase segment begins. As can be seen from Figure 8, the slope of the displacement and force change curves are clearly altered. These changes can be attributed to the change in the stiffness of the support. The overall displacement of the leg is $h^{\prime}=7071.18-6995.45=75.73 \mathrm{~mm}$ and the calculated result from Section 2.3 is $h=76 \mathrm{~mm}$. Since $h \approx h^{\prime}$, the model is of high feasibility and reliability.

In order to facilitate the placement of the impact load, another model is tested. The same load is applied on the canopy above the leg (socket) without the simulated roof (Figure 9). The results are the same. Therefore, the static pressure of the simulated roof can be replicated by applying the concentrated force on the socket.

\section{Influence of Impact Loading Position on the Hinge Point Force}

4.1. Analysis of the Position of the Impact Load. With the continuous advance of the working face, breaks in the immediate roof and the main roof form the periodic weighting. This, combined with the random rock bursts, forms the impact loading that acts on the support. Ideally, the canopy of the

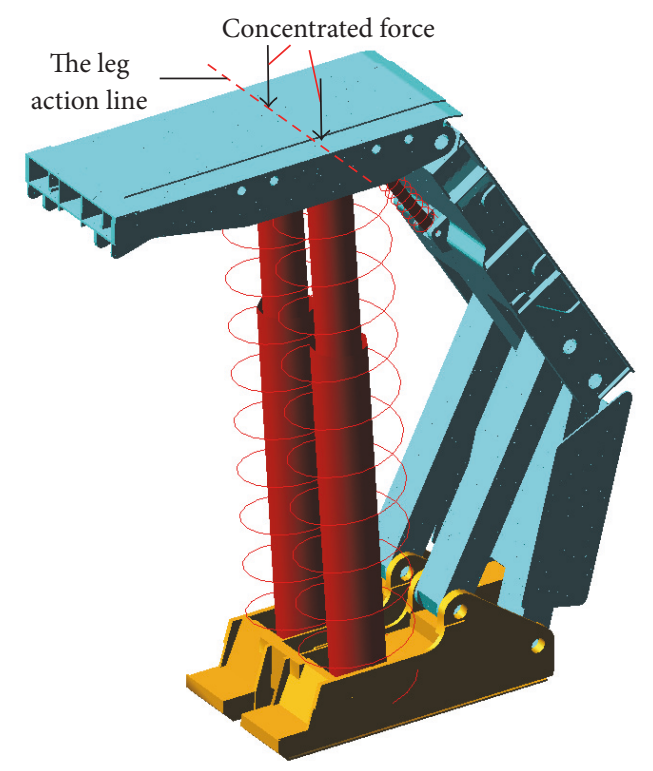

FIgURE 9: Numerical model with the concentrated force on the socket.

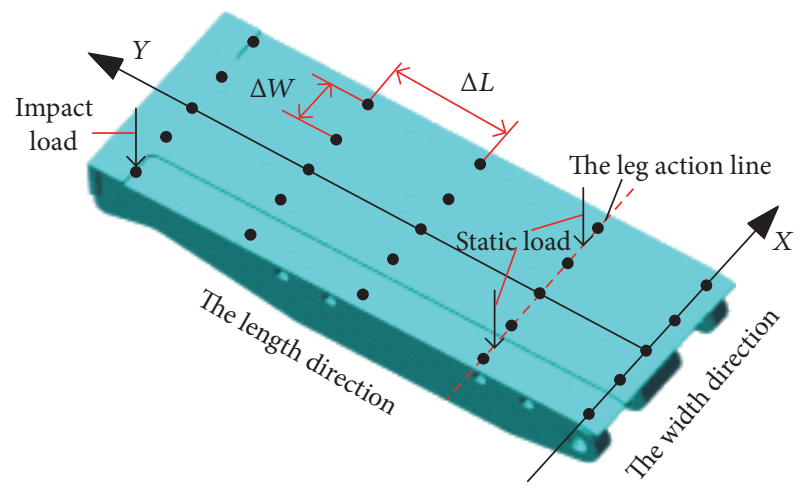

FIgURE 10: Location of the impact load.

support is in full contact with the roof. Thus, the resultant force from the impact load is located near the leg action line. The force is transferred to the goaf shield and the base through the legs and the equilibrium. However, in reality, the underground conditions are complex and changeable and the shearer usually cuts the roof unevenly. Thus, contact between the canopy and the roof is usually sporadic and irregular. In this case, when impact loading occurs, poor contact conditions can lead to unexpected failure of the support. Therefore, it is of significant importance to analyze the force transfer characteristics of the hinge joints of the hydraulic support when the impact load is acting on different parts of the canopy [20].

The width direction of the canopy is defined as the $X$ axis and the length direction as the $Y$ axis. The impact point is taken every $1000 \mathrm{~mm}(\Delta L)$ along the length direction and every $400 \mathrm{~mm}(\Delta W)$ along the width direction (Figure 10). A static load of $18500 \mathrm{kN}$ is applied on the socket and an impact load of $1500 \mathrm{kN}$ is applied at each impact point. In order to 


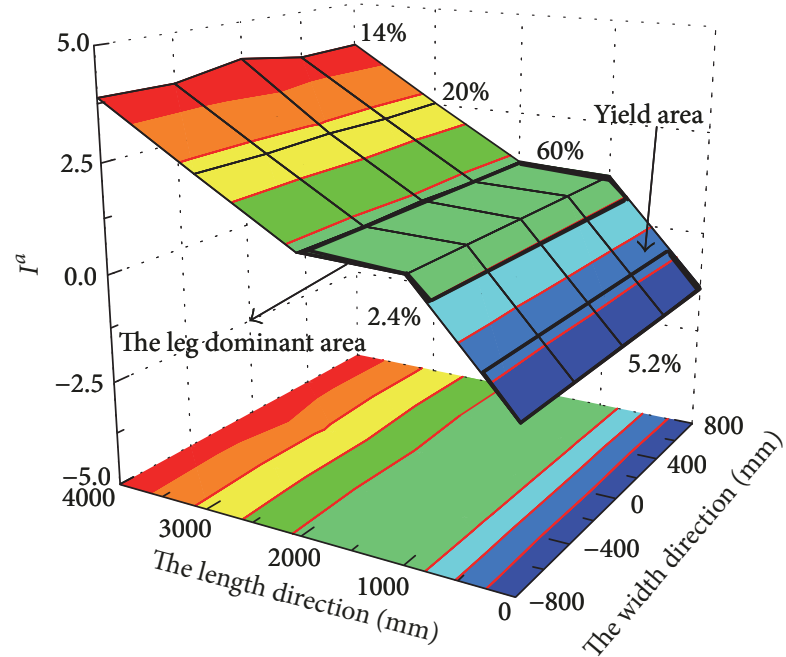

FIGURE 11: The impact coefficient and excitation coefficient of the equilibrium jack.

evaluate the results, scale transmissions are done using (12), namely, the impact coefficient and excitation coefficient.

$$
\begin{aligned}
I_{(x, y)}^{i} & =\frac{F_{i \max }-F_{i o}}{F_{I}}, \\
L_{(x, y)}^{i} & =\frac{F_{i \max }-F_{i s}}{F_{i s}} \times 100 \%,
\end{aligned}
$$

where $I_{(x, y)}^{i}$ is the impact coefficient of the $i$ th hinge point, while the impact load acts at $(x, y) ; L_{(x, y)}^{i}$ is the excitation coefficient of the $i$ th hinge point, while the impact load acts at $(x, y)$ (if not specifically pointed out, $L^{i}$ is the average value of the five points in the same width direction); $F_{i \max }$ is the peak force response of the $i$ th hinge point caused by the impact loading; $F_{i o}$ is the force on the $i$ th hinge point caused by the static load; $F_{i s}$ is the stable force response of the $i$ th hinge point caused by the impact loading; and $F_{I}$ is the impact force $(1500 \mathrm{kN}$ in this study).

4.2. Influence on the Hinge Point Force of the Equilibrium Jack. The impact coefficient $\left(I^{a}\right)$ and the excitation coefficient $\left(L^{a}\right)$ at the hinge point of the equilibrium jack are shown in Figure 11 as the position of the impact load changes. Due to the fact that the selected support has only one equilibrium jack, the variation of the equilibrium jack is strictly symmetrical, while the impact loading varies along the width direction of the support. When the position of impact load changes along the width of the canopy, the change of $I^{a}(2 \%)$ is far less than that caused by the change in the length direction (201\%). When the impact load moves backward, $I^{a}$ decreases gradually and then reverses (except the leg dominant area). This means that the equilibrium jack gradually changes from a tension to a compression state to adapt to the change of the external load position. Besides, the support has a trend of back tilting (see Figure 12). In the leg dominant area, the impact coefficient is almost unchanged.

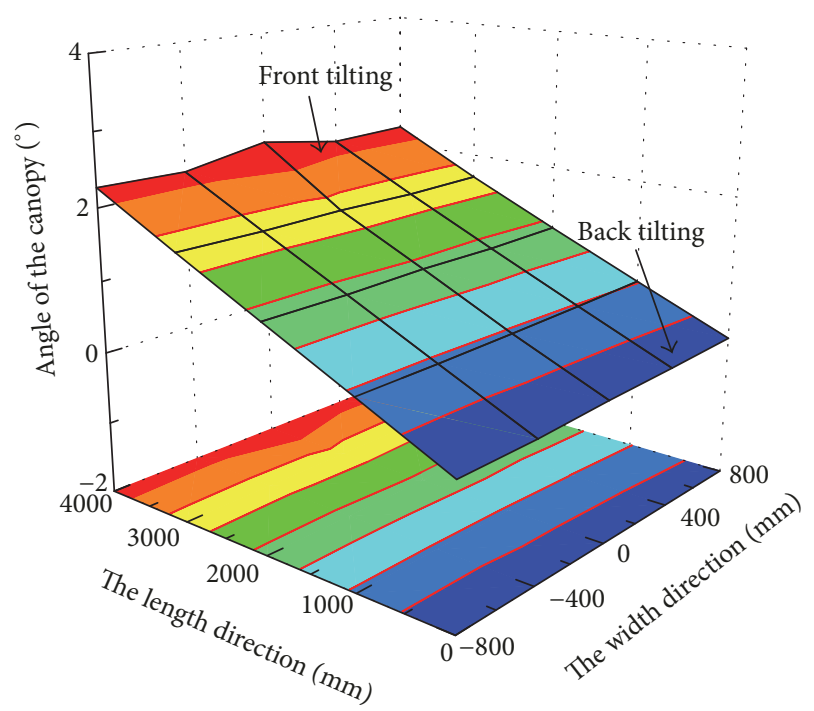

FIGURE 12: Rotation angle of the canopy.

At this time, the impact load is mainly borne by the leg; the equilibrium jack does not need to balance the additional torque caused by the impact load.

With a decrease in equilibrium jack force, $L^{a}$ increases gradually. $L^{a}$ reaches a maximum when the impact force acts on the leg action line (60\%). It can also be seen that the jack force is close to its rated working resistance when the impact force acts at the front end of the canopy. When the impact force acts at the back end of the canopy, the rod side of the jack reaches the setting pressure of the relief valve (yield area). The results show that the self-stability and carrying capacity of the support are very poor when the load acts on both ends of the support under this single region loading condition.

4.3. Influence on the Hinge Point Force of the Lemniscate Bars. The impact coefficients of the lemniscate bars at the hinge point are shown in Figures 13(a) and 13(b) as the position of the impact load changes. When the impact load moves backward, the force of the front bar $\left(I^{c}\right)$ is basically unchanged in the beginning, while the force of the rear bar $\left(I^{d}\right)$ decreased gradually. When the impact load passes through the leg action line, $I^{c}$ and $I^{d}$ increase rapidly. Along the width direction, as the load moves rightward (towards the monitoring point), $I^{c}$ increases gradually, while $I^{d}$ decreases initially but then increases slowly.

Since the steady-state forces of the lemniscate bars have opposite trends, a new coefficient called "steady-state force impact coefficient $\left(I_{S}^{i}\right)$ " is introduced. $I_{S}^{i}$ can be calculated using (13). The steady-state force impact coefficients of the bars are shown in Figures 14(a) and 14(b). When the impact load moves backward, the steady-state force of the front $\left(I_{S}^{c}\right)$ and rear $\left(I_{S}^{d}\right)$ bar hinge joints increases gradually. Along the width direction, as the load moves rightward (toward the monitoring point), $I_{S}^{c}$ increases slowly, while $I_{S}^{d}$ decreases.

$$
I_{S}^{i}=\frac{\left(F_{i s}-F_{i o}\right)}{F_{i o}} .
$$




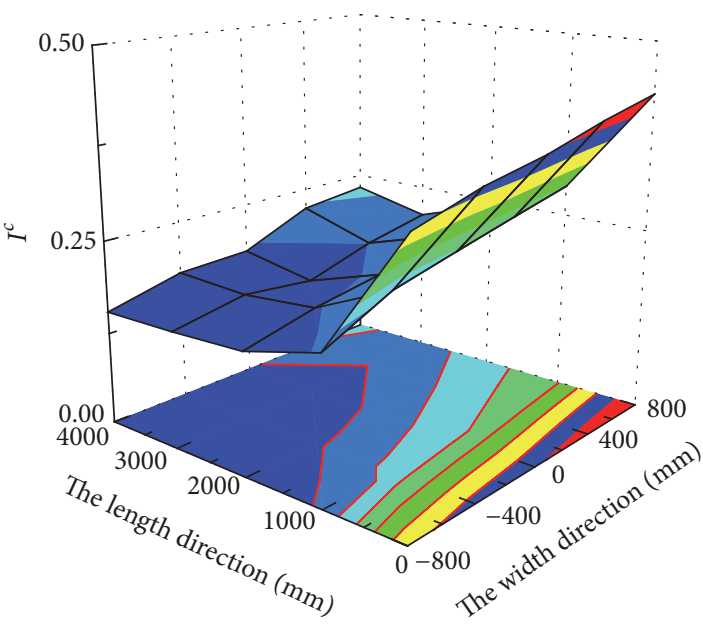

(a) The front bar

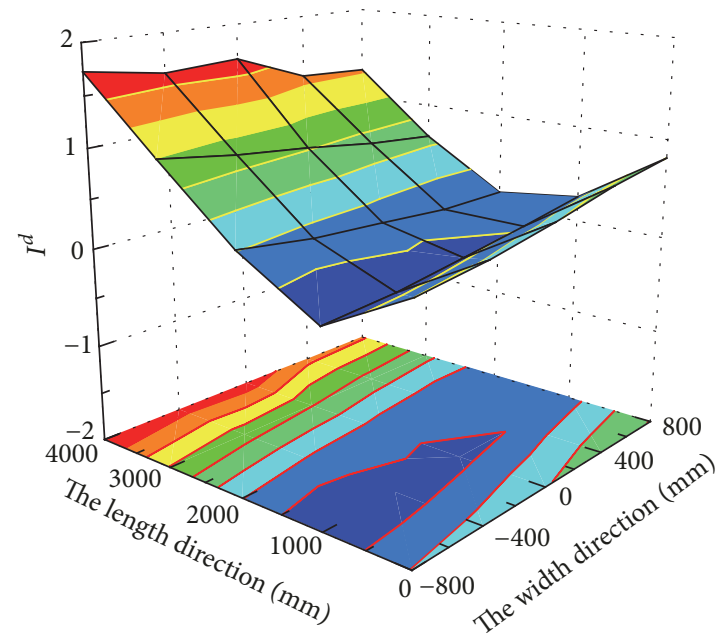

(b) The rear bar

FIgURE 13: The impact coefficients of the lemniscate bars.

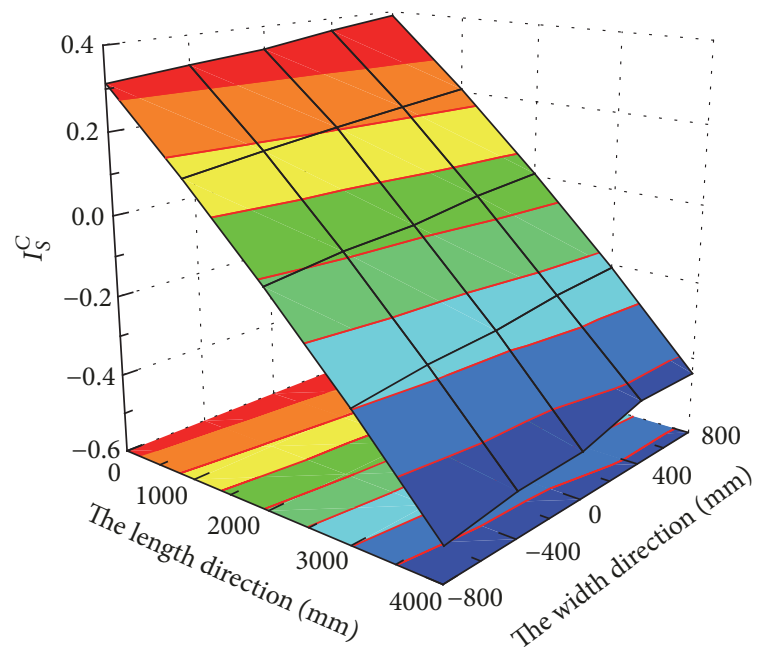

(a) The front bar

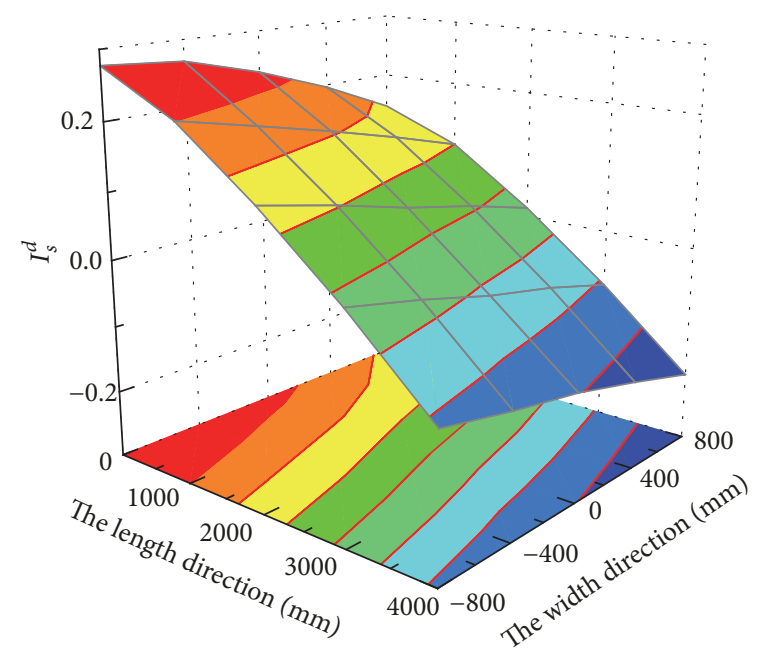

(b) The rear bar

FIGURE 14: The steady-state force impact coefficients of the lemniscate bars.

The excitation coefficients of the lemniscate bars are shown in Figure 15 (average value across the width direction). As can be seen, the excitation force $(25 \% \sim 30 \%)$ of the lemniscate bars caused by impact loading acting on the front end of the canopy is much larger than that of the force acting on the rear end (1\% 3\%).

\subsection{Influence on the Hinge Point Force between the Canopy} and the Goaf Shield. The impact coefficient $\left(I^{b}\right)$ and the excitation coefficient $\left(L^{b}\right)$ of the hinge point force between the canopy and goaf shield are shown in Figure 16. When the impact load moves backward and rightward, $I^{b}$ initially decreases but then rises with the leg action line as the boundary (similar to $I^{d}$, but the impact effect is more severe). The excitation effect $\left(L^{b}\right)$ at both ends of the canopy is about
$10 \%$ but is only $0.4 \% \sim 3 \%$ near the leg action line. Figure 16 indicates that the impact loading has little effect on $L^{b}$.

\section{Conclusions}

(1) From the point of view of stiffness, the working process of a shield support is analyzed and is redefined in five stages, namely, active setting, passive setting, rapid increase, overflow, and unloading. The rationality of this definition is discussed by means of constructing the equivalent stiffness model of the doubly telescopic leg and the numerical simulation of the support loading.

(2) The position of the impact load has different influence on the hinge point force of the shield support. In general, due to the large length-width ratio (270\%), the impact effect and 


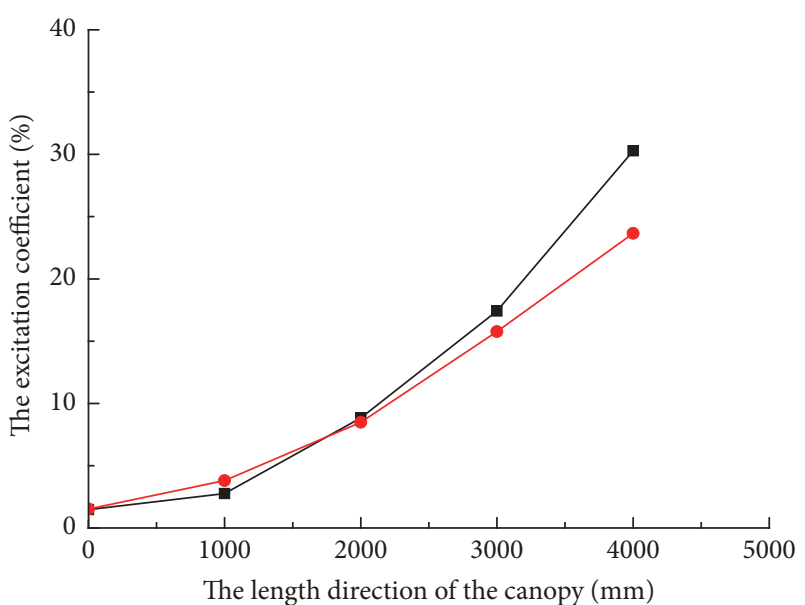

$\rightarrow-$ The front bar $\left(L^{c}\right)$

- The rear bar $\left(L^{d}\right)$

FIGURE 15: The excitation coefficients of the lemniscate bars.

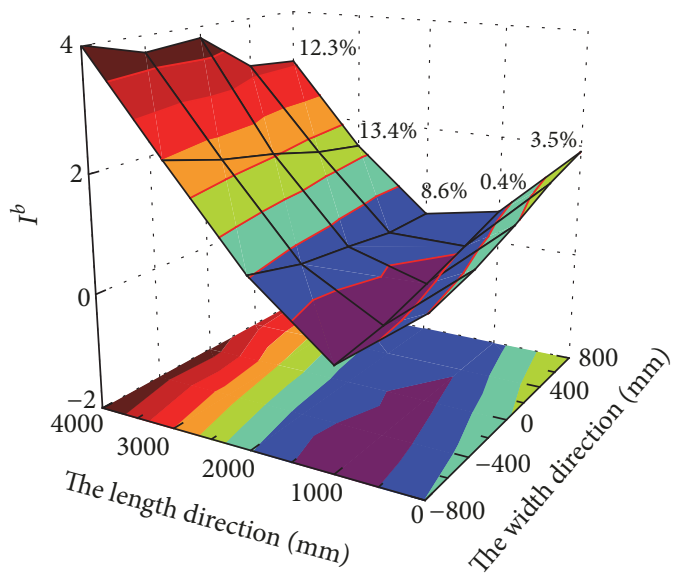

FIGURE 16: The impact coefficient and the excitation coefficient of the hinge point force between the canopy and goaf shield.

the excitation effect are more obvious when the impact load moves along the length direction.

(3) The impact effect, $I^{a}$ and $I^{b}$, is most significant when the position of the impact load changes (400\%). The excitation effect, $L^{c}$ and $L^{d}$, is most significant when the position of the impact load changes (25\% 30). The additional moment produced by the impact load is minimised when it is acting on the leg action line. At this point, both the impact effect and the excitation effect reach their lowest $(0.1 \% \sim 3 \%)$, which means that the optimal equilibrium region of the support is located near the leg action line.

(4) There is a positive correlation between the working resistance of the equilibrium jack and the position of the impact load in the length direction. When the impact load moves backward, the working resistance of the equilibrium jack decreases gradually and is eventually reversed. The equilibrium capacity of the equilibrium jack is poor when the impact load is applied behind the leg action line. The bearing capacity of the support can be improved by increasing the front-to-rear ratio of the canopy within a reasonable range.

\section{Conflicts of Interest}

The authors declare that there are no conflicts of interest regarding the publication of this paper.

\section{Acknowledgments}

The research described in this paper was financially supported by the National Natural Science Foundation of China (no. 51375282), the Natural Science Foundation of Shandong Province, China (no. ZR2014EEM021), and Science and Technology Development Program of Shandong Province, China (no. 2014GGX103043).

\section{References}

[1] S. S. Peng, Longwall Mining, West Virginia University, Department of Mining Engineering, Morgantown, WV, USA, 2nd edition, 2006.

[2] T. M. Barczak and M. Engineer, "A retrospective assessment of longwall roof support with a focus on challenging accepted roof support concepts and design premises," in Proceedings of the in Proceedings of the 25th International Conference on Ground Control in Mining, pp. 232-244, Morgantown, WV, USA, 2006.

[3] European standard EN 1804-1-2001, Machines for underground mines - safety requirements for hydraulic powered roof supports - Part 1: Support units and general requirements, 2001.

[4] M. Witek and S. Prusek, "Numerical calculations of shield support stress based on laboratory test results," Computers \& Geosciences, vol. 72, pp. 74-88, 2016.

[5] A. Mangal and P. S. Paul, "Rock mechanical investigation of strata loading characteristics to assess caving and requirement of support resistance in a mechanized powered support longwall face," International Journal of Mining Science and Technology, vol. 26, no. 6, pp. 1081-1087, 2016.

[6] R. C. Frith, "A holistic examination of the load rating design of longwall shields after more than half a century of mechanised longwall mining," International Journal of Mining Science and Technology, vol. 25, no. 5, pp. 687-706, 2015.

[7] Y.-L. Tan, W.-Y. Guo, Q.-H. Gu et al., "Research on the Rockburst Tendency and AE Characteristics of Inhomogeneous Coal-Rock Combination Bodies," Shock and Vibration, vol. 2016, Article ID 9271434, 2016.

[8] N. Hosseini, K. Goshtasbi, B. Oraee-Mirzamani, and M. Gholinejad, "Calculation of periodic roof weighting interval in longwall mining using finite element method," Arabian Journal of Geosciences, vol. 7, no. 5, pp. 1951-1956, 2014.

[9] G. Fan, D. Zhang, and X. Wang, "Mechanism of roof shock in longwall coal mining under surface gully," Shock and Vibration, vol. 2015, Article ID 803071, 2015.

[10] G. S. P. Singh and U. K. Singh, "A numerical modeling approach for assessment of progressive caving of strata and performance of hydraulic powered support in longwall workings," Computers \& Geosciences, vol. 36, no. 7, pp. 1142-1156, 2009.

[11] G. S. P. Singh and U. K. Singh, "Prediction of caving behavior of strata and optimum rating of hydraulic powered support for longwall workings," International Journal of Rock Mechanics and Mining Sciences, vol. 47, no. 1, pp. 1-16, 2010. 
[12] K. Holub, J. Rušajová, and J. Holečko, "Particle velocity generated by rockburst during exploitation of the longwall and its impact on the workings," International Journal of Rock Mechanics and Mining Sciences, vol. 48, no. 6, pp. 942-949, 2011.

[13] A. K. Verma, "Numerical analysis of an interaction between hydraulic-powered support and surrounding rock strata," International Journal of Geomechanics, vol. 13, no. 2, pp. 181-192, 2013.

[14] F. Gao, D. Stead, and J. Coggan, "Evaluation of coal longwall caving characteristics using an innovative UDEC Trigon approach," Computers \& Geosciences, vol. 55, pp. 448-460, 2014.

[15] M. Shabanimashcool, L. Jing, and C. C. Li, "Discontinuous Modelling of Stratum Cave-in in a Longwall Coal Mine in the Arctic Area," Geotechnical and Geological Engineering, vol. 32, no. 5, pp. 1239-1252, 2014.

[16] S. S. Peng, "What can a shield leg pressure tell us?" Coal Age, pp. 54-57, 1998.

[17] R. Trueman, G. Lyman, and A. Cocker, "Longwall roof control through a fundamental understanding of shield-strata interaction," International Journal of Rock Mechanics and Mining Sciences, vol. 46, no. 2, pp. 371-380, 2009.

[18] J. Y. Cheng, Z. J. Wan, S. S. Peng, S. F. Liu, and Y. L. Ji, "What can the changes in shield resistance tell us during the period of shearer's cutting and neighboring shields' advance?" International Journal of Mining Science and Technology, vol. 25, no. 3, pp. 361-367, 2015.

[19] S. Prusek, M. Płonka, and A. Walentek, "Applying the ground reaction curve concept to the assessment of shield support performance in longwall faces," Arabian Journal of Geosciences, vol. 9, no. 3, article no. 167, pp. 1-15, 2016.

[20] L.-C. Liang, J.-J. Tian, H. Zheng, and S.-J. Jiao, "A study on force transmission in a hydraulic support under impact loading on its canopy beam," Journal of the China Coal Society, vol. 40, no. 11, pp. 2522-2527, 2015.

[21] T. M. Barczak, "A First Step In Developing Standing Roof Support Design Criteria Based on Ground Reaction Data For Pittsburgh Seam Longwall Tailgate Suppor," in Proceedings of the in Proceedings of the 27th International Conference on Ground Control in Mining, pp. 349-359, Morgantown, WV, USA, 2008.

[22] E. T. Brown, J. W. Bray, B. Ladanyi, and E. Hoek, "Ground response curves for rock tunnels," Journal of Geotechnical Engineering, vol. 109, no. 1, pp. 15-39, 1983.

[23] T. P. Medhurst, "Practical Considerations in Longwall Support Behaviour and Ground Response," Journal of the American Society for Mass Spectrometry, vol. 16, no. 10, pp. 1583-1594, 2005.

[24] T. P. Medhurst and K. Reed, "Ground response curves for longwall support assessment," Institution of Mining and Metallurgy. Transactions. Section A: Mining Technology, vol. 114, no. 2, pp. A81-A88, 2005.

[25] T. Barczak and D. Gerhart, "Performance and safety considerations of hydraulic support system," in Proceedings of the in Proceedings of the 17th International Conference on Ground Control in Mining, pp. 176-186, Morgantown, WV, USA, 1998. 


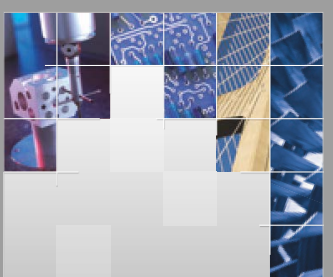

\section{Enfincering}
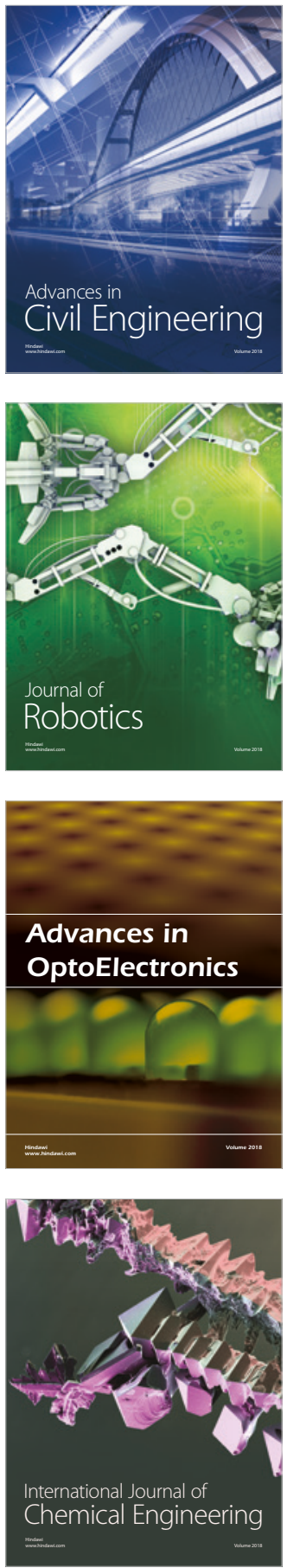

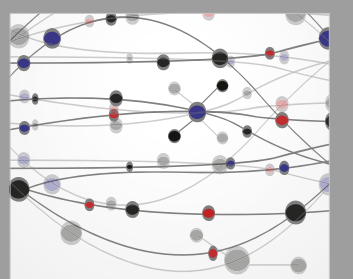

\section{Rotating \\ Machinery}

The Scientific World Journal

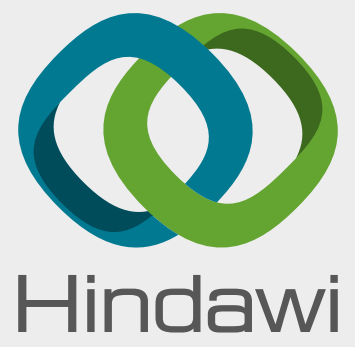

Submit your manuscripts at

www.hindawi.com
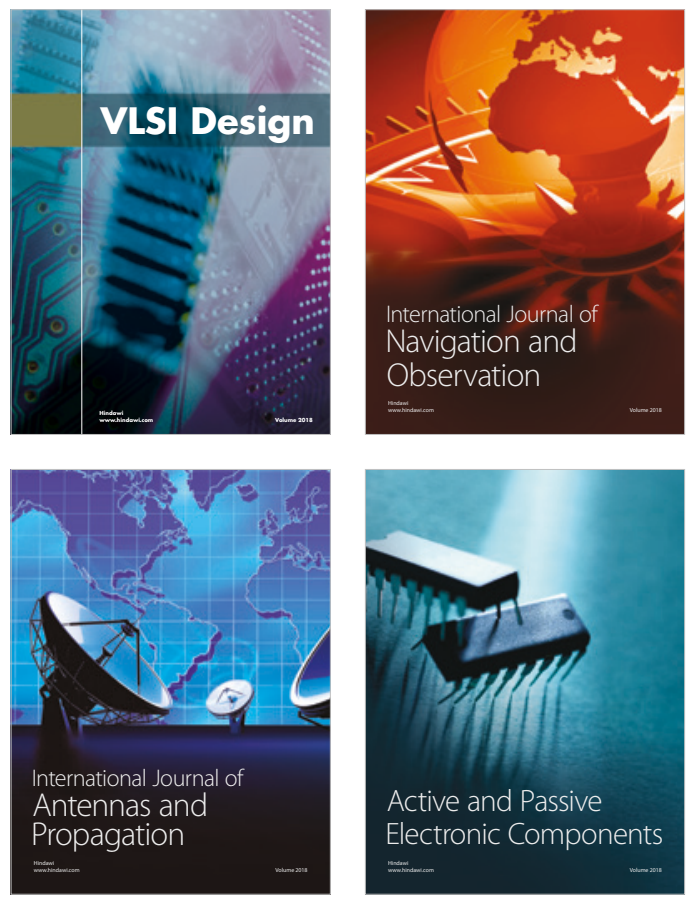
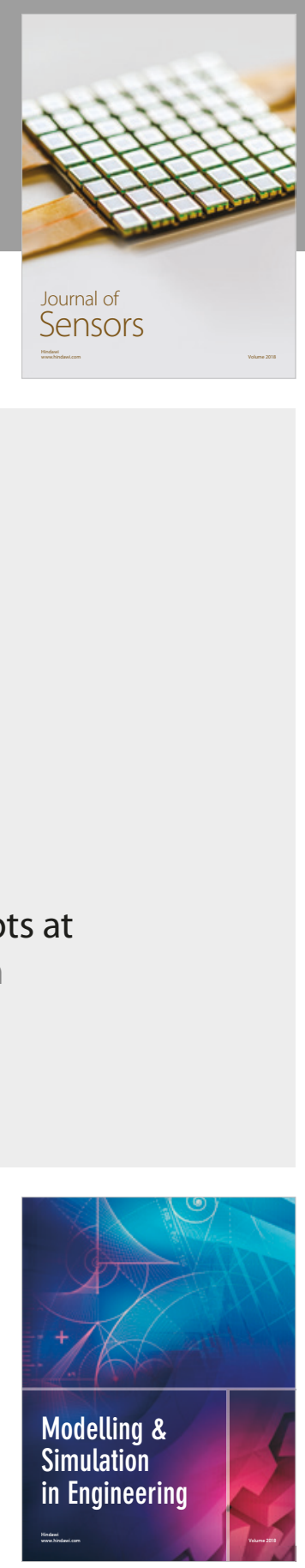

\section{Advances \\ Multimedia}
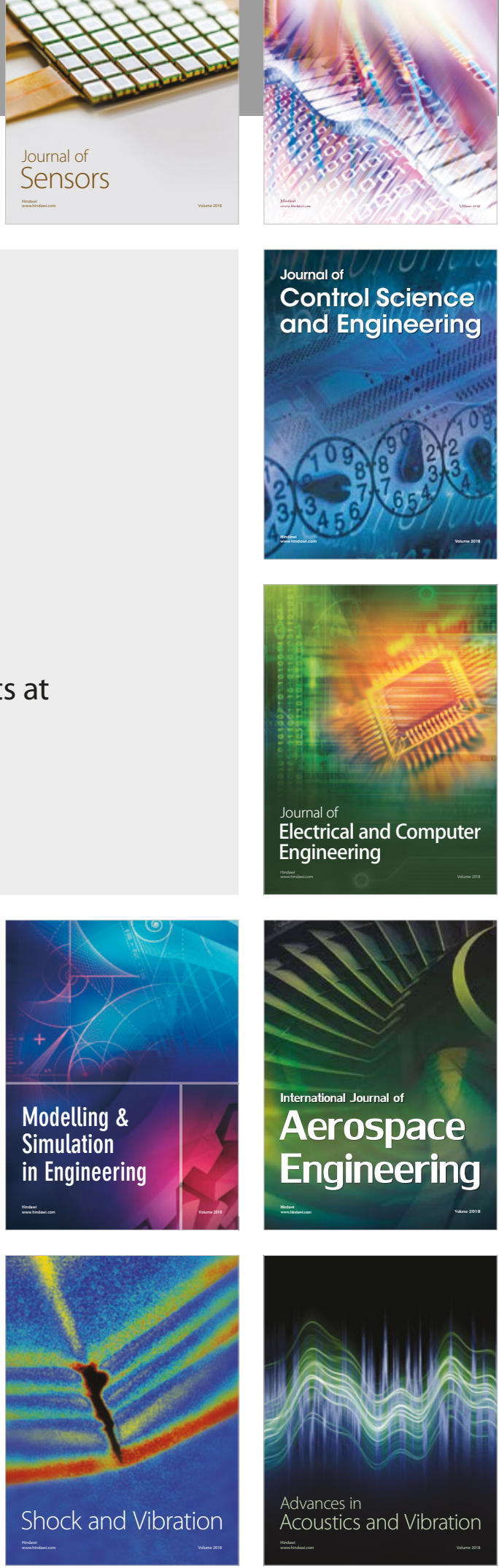